\title{
Sexuality, disability and human rights: Strengthening healthcare for disabled people
}

The World Report on Disability ${ }^{1}$ by the World Health Organization and the World Bank marks a watershed in the history of how disability should be understood by healthcare practitioners. Along with a special issue of the Lancet, ${ }^{2}$ this report marks recognition by organised healthcare that healthcare practitioners acted paternalistically towards disabled people, often deciding on their behalf what is in their best interests. ${ }^{3}$ South Africa favours a human rights approach to disability, where the Constitution mentions non-discrimination on the grounds of disability, and globally through the promulgation of the United Nations Convention on the Rights of Persons with Disabilities (UNCRPD). ${ }^{4}$ Historically, health practitioners have underestimated the capacities of disabled people and from clinical encounters view disability as an illness, whereas in reality most disabled people are not ill.

This change in how disability is viewed changes the ways in which interactions between the health professions and disabled people are seen. An optimal emancipatory approach gives maximum choice and control to disabled people in all matters in their lives, including health. This is especially pertinent in the field of sexuality and disability. ${ }^{6}$ Health professionals have been seen as complicit in denying disabled people their rights to sexual expression and sexual choices, and in perpetuating myths about disabled people. On the one hand, disabled people have been viewed as asexual or as eternal children, and on the other they have been viewed as sexually rampant and unable to control sexual impulses. ${ }^{7}$ However, the new emphasis on sexual rights as part of human rights for disabled people may create dilemmas for clinicians caring for patients who are disabled, especially in South Africa in the context of high rates of sexual violence and of HIV/AIDS. The magnitude of the HIV/AIDS epidemic forces clinicians to think critically about the sexuality of disabled people and how the epidemic affects them. ${ }^{8}$

Ethicist Jacob Appel holds contemporary views of the right to sexuality and to sexual liberty for disabled people:. 'Sexual rights are a fundamental element of human rights. They encompass the right to experience pleasurable sexuality, which is essential in and of itself and, at the same time, is a fundamental vehicle of communication and love between people. Sexual rights include the liberty and autonomy in the responsible exercise of sexuality.' Researchers and healthcare practitioners corroborate these views. Murphy and Elias, ${ }^{10}$ who are experienced paediatricians based in the USA, suggest that all paediatricians who treat children or adolescents with disabilities 'introduce issues of physical, cognitive and psychosexual development to parents and their children at an early age and continue discussions at most visits throughout adolescence and adulthood. They also advise that parents of young people with developmental disabilities 'optimize independence, self-care, social skills and developmentally appropriate sexuality education in home, community and school settings' Eastgate, ${ }^{11}$ a family practitioner in Australia, suggests that disability organisations assist in providing education to young, disabled women, particularly in menstrual management, hygiene and sexuality. In the UK there have been efforts to support disabled parents, acknowledging that disabled men and women also have the right to experience parenthood. ${ }^{12}$

The Western Cape Forum for Intellectual Disability (WCFID) has produced manuals to guide sexuality and HIV prevention education for intellectually disabled adults and adolescents. These acknowledge that sexuality is core to the experience of being human and that people with intellectual disabilities have a right to a positive sexuality. The manuals illustrate with adequate visual resources, appropriate sexual expression, access to HIV testing and how to disclose sexual abuse. ${ }^{13}$

While it is easy to exhort practitioners who work in primary healthcare or in services focusing on HIV/AIDS or sexual health to be more open about disability issues, they may face many challenges in attempting to do so.
Clinician discomfort. Many people, including clinicians, feel uncomfortable discussing sexual matters, discomfort which may increase in the context of disability. ${ }^{3}$ Mgwili and Watermeyer ${ }^{3}$ reported that physically disabled women accessing family planning were treated as if they were asexual by clinicians, who berated them for being sexually active. Disabled people are well aware of this discomfort. Wallis ${ }^{14}$ expressed his experiences as a person with muscular dystrophy: 'The issue of sexuality and disability is in the main brushed under the carpet. Some of my carers have been visibly embarrassed when sex has been mentioned or shown on a TV programme we have watched together. The general public do not view disabled people as sexual beings and many professionals and family members who are too uncomfortable to address this issue openly share this attitude. Strangely, talking to people - especially parents and carers - about death and dying may be easier than talking to them about sex.'

The solution to this issue goes beyond educating practitioners, as researchers in a similar field have shown. Kai et al. ${ }^{15}$ reported that, paradoxically, as a group of clinicians in the UK learned more about the importance of cultural sensitivity in healthcare, the less confident they felt in managing cross-cultural healthcare consultations, partly through fear of violating cultural norms of which they had recently been made aware. There may be similar challenges for clinicians in dealing with issues of disability and sexuality - the more practitioners are made aware of the legacy of patronising and inappropriate attitudes towards the sexuality of disabled people, the more difficult they may find it to intervene, for fear of perpetuating a legacy of oppressive healthcare.

Fear of encouraging sexual activity. Rohleder and Swartz ${ }^{16}$ found that educators of disabled youth were not opposed to delivering sexual health education to youth with disabilities; nor did they wish to deny them capacity for a meaningful sexual relationship. However, they were worried that if they distributed condoms to these young people, this would precipitate high-risk sexual behaviour. Similarly, Collins ${ }^{17}$ found that clinicians working in mental health services would distribute condoms to patients they believed were already sexually active, or who had a sexually transmitted infection or had been sexually abused. Condoms were not distributed to patients whom they perceived to be too ill to use them, and they were also concerned about encouraging sexual activity.

Worry about risk of sexually transmitted infections, HIV risk and death. Particularly in the case of people with intellectual or psychiatric disabilities, or with other forms of brain pathology that may affect planning and judgement (temporary, intermittent or permanent), clinicians may worry that supporting sexual rights may expose people to potentially life-threatening risks. It is often difficult for clinicians in the short time they have with patients to assess their capacity to take responsibility for their sexual health and that of partners, or the context of support patients may have around sexual health. Worry about sexual risk may encourage clinicians to err on the side of over-protection as the safest route to take. ${ }^{16}$

Cultural and religious norms. Many disabled children and adolescents attend schools that have a religious ethos. For example, Mall ${ }^{18}$ found discomfort about condom education in schools for deaf and hard-ofhearing adolescents that had a Catholic ethos. Some educators in Catholic schools thought it was important to uphold their ethos in their teaching and therefore did not conduct condom demonstrations or educate about condom usage during Life Orientation or sex education. Clinicians working with disabled people must take this into account. and may have to confront and consider their own cultural and religious views on sexuality and whether they affect their care for disabled people.

The role of institutions. A problem with providing appropriate emancipatory sexual healthcare for disabled people, including adults, is that they are more likely than others to live in institutions. Although many 


\section{EDITORIAL}

institutions engage proactively to support the sexual rights of disabled people, others have a long way to go. Clinicians may experience conflict between their own views about sexuality and those of the institution, and may not wish their patients to come into conflict with staff who have considerable influence over their lives. Even where disabled adults live with their parents or other family members, these relatives may wish to prevent them from having sex, and this may result in conflict with health professionals..$^{19}$

\section{Conclusion}

Healthcare practitioners face dilemmas in providing sexual healthcare to disabled patients. Although the HIV/AIDS epidemic has forced critical thinking about some of these issues, obstacles remain to encouraging a completely emancipatory approach. A balance must be sought, given that disabled people have a right to a healthy sexuality and should be advised of the risk of sexual abuse and HIV infection. The clinician's own discomfort is a large and hidden issue, occasioned not through individual failings but through socialisation, which affects many people. We suggest that clinicians who face dilemmas regarding the sexual rights and responsibilities of their patients discuss these with colleagues. Clinicians may need to support one another in treading the difficult path between promotion of rights and protection of vulnerabilities.

\section{Sumaya Mall \\ Leslie Swartz \\ Department of Psychology \\ Stellenbosch University}

Corresponding author: S Mall (sumaya.mall@gmail.com)
1. World Health Organization and World Bank. World Report on Disability. Geneva: WHO, 2011.

2. Horton R. Disability. Beyond the medical model. Lancet 2009;374:1793. [http://dx.doi.org/10.1016/S01406736(09)62043-2]

3. Mgwili VN, Watermeyer B. Physically disabled women and discrimination in reproductive health care Psychoanalytic reflections. In: Watermeyer B, Swartz L, Lorenzo T, Schneider M, Priestly M, eds. Disability and Social Change. Cape Town. HSRC Press, 2006.261-272.

4. United Nations. Convention on the Rights of Persons with Disabilities. http://www.un.org/disabilities/ convention/conventionfull.shtml (accessed 11 June 2012).

5. Salvador-Carulla L, Saxena S. Intellectual disability: between disability and clinical nosology. Lancet 2009;374:1798-1799. [http://dx.doi.org/10.1016/S0140-6736(09)62034-1]

6. Shakespeare T, Gillespie-Sells K, Davies D. The Sexual Politics of Disability: Untold Desires. London: Cassell, 1996.

7. Milligan NS, Neufeldt AH. The myth of asexuality: A survey of social and empirical medicine. Sexuality and Disability 2001;19:91-109. [http://dx.doi.org/10.1023/A:1010621705591]

8. Fritz G. Sexuality education for the developmentally disabled. Brown University Child and Adolescent 8. Fritz G. Sexuality education
Behavior Letter 2003;9:8.

9. Appel JM. Sex rights for the disabled? Journal of Medical Ethics 2010;36:152-154. [http://dx.doi. org/10.1136/jme.2009.033183]

Org/10.1136/jme.2009.033183] 2006;118:398-403. [http://dx.doi.org/10.1542/peds.2006]

11. Eastgate G. Sexual health for people with intellectual disability. Salud Publica De Mexico 2008;50(Suppl 2):255-259.

12. Morris J, Wates M. Supporting Disabled Parents and Parents with Additional Support Needs. Social Care Institute for Excellence. Bristol: Policy Press, 2006:1-229.

13. Johns R. Step by Step: A Sexuality and HIV/AIDS Education Programme for Young Adults with Intellectua nual. Cape Town: 2005:1-157.

14. Wallis N. My lifelong desire. 15 January 2007. http://www.guardian.co.uk//society/2007/jan/15/health. socialcare (accessed 9 June 2012).

15. Kai J, Beavan, J, Faull C, Dodson L, Gill P, Beighton A. Professional uncertainty and disempowerment Responding to ethnic diversity in health care: A qualitative study. PLoS Med 2007;4:1766-1775. [http:/ dx.doi.org/10.1371/journal.pmed.0040323

16. Rohleder P, Swartz L. Providing sex education to persons with learning disabilities in the era of HIV/AIDS Tensions between discourses of human rights and restriction. J Health Psychol 2009;14:601-610. [http:// dx.doi.org/101177/1359105309103579]

17. Collins PY. Challenges to HIV prevention in psychiatric settings: Perceptions of South African ment health care providers. Soc Sci Med 2006;63:979-990. [http://dx.doi.org/10.1016/j.socscimed.2006.03.003]

18. Mall S. HIV prevention issues for Deaf and hard of hearing adolescents: Views of parents, teachers adolescents and organizations serving the Deaf community. Unpublished PhD thesis, Stellenbosch University, 2012:1-217

19. Cuskelly M, Bryde R. Attitudes towards the sexuality of adults with an intellectual disability: parents, suppor staff, and a community sample. Journal of Intellectual and Developmental Disability 2004;29(3):255-264 [http://dx.doi.org/10.1080/13668250412331285136]

S Afr Med J 2012;102(10):792-793. DOI:10.7196/SAMJ.6052 